\title{
SOBRE LA CONCEPCIÓN MAQUIAVÉLICA DEL BUEN PRÍNCIPE
}

\author{
RAFAEL SIMIAN \\ Universidad de los Andes (Chile)
}

\begin{abstract}
RESUMEN: Tradicionalmente, se ha leído El Príncipe de Maquiavelo como una obra que defiende un nuevo ideal ético-político que busca invalidar y reemplazar los ideales de Cicerón y el cristianismo. Con todo, Cassirer, Viroli y Berlin han defendido, cada uno a su manera, que ello no es así. Este ensayo expone las lecturas de estos tres intérpretes y extrae de ellas sus puntos centrales, con el fin de examinar los escritos de Maquiavelo y comprobar si acaso aquellos puntos son correctos. El análisis textual concluye que la lectura tradicional es plausible, mientras que las otras tres son poco convincentes. Se hace hincapié, empero, en que el ideal ético-político de Maquiavelo en El Príncipe posee restricciones importantes: primero, no es un ideal para todo ser humano; y segundo, solo es válido bajo ciertas circunstancias políticas ajenas a nuestro control, las cuales hacen necesaria la realización de ese ideal para la vida y prosperidad de la comunidad.
\end{abstract}

PALABRAS CLAVE: Nicolás Maquiavelo; El Príncipe; Ernst Cassirer; Maurizio Viroli; Isaiah Berlin; ética.

\section{On Machiavelli's Conception of the Good Prince}

ABSTRACT: Traditionally, Machiavelli's Prince has been read as defending a new ethico-political ideal, thus aiming to invalidate and replace those of Cicero and of Christianity. However, Cassirer, Viroli, and Berlin have argued, each in their own way, that this is not true. The essay presents these interpreters' readings and highlights their main points. Then it examines Machiavelli's texts to see whether those points are correct. The textual analysis leads to the conclusion that the traditional reading is plausible, whereas the other three are unconvincing. Stress is made on the fact that Machiavelli's ethico-political ideal in The Prince involves serious restrictions: First, it is not an ideal valid for everybody; and second, it is valid only under certain political circumstances which escape our control and make it necessary for the life and prosperity of the community.

KEY WORDS: Niccolò Machiavelli; The Prince; Ernst Cassirer; Maurizio Viroli; Isaiah Berlin; Ethics.

Si es verdad, como insiste Aristóteles, que la ética no es una disciplina meramente teórica, sino un estudio que nos ayuda a ser más capaces de alcanzar nuestro bien, entonces El Príncipe de Maquiavelo parece ser con toda claridad una obra ética ${ }^{1}$. Cada consideración, cada precepto, da la impresión de nacer y encontrar su lugar propio en el contexto de una nueva concepción del buen príncipe, un modelo que pretende invalidar y reemplazar los ideales comunes de esa época, principalmente derivados de Cicerón y del cristianismo. Todo el que ascienda o pretenda ascender al poder de un principado sería llamado en esta obra a revisar su actuar y su idea del bien político a la luz de la crítica maquiavélica.

Esta lectura o aproximación general ha parecido obvia a muchos. De ahí que Maquiavelo sea tenido comúnmente por un autor impío, perverso e instigador

1 Véase Aristóteles, Ethica Nicomachea, ed. Bywater, I., Oxford University Press, Oxford 1894, I.2, 1094a23-25; I.3, 1095ª $6-7$. 
del $\mathrm{mal}^{2}$. Sin embargo, hay intérpretes que han desafiado, e incluso rechazado tajantemente, esta visión de El Príncipe. Ernst Cassirer, por ejemplo, ha concluido que Maquiavelo no se habría propuesto ofrecer ninguna concepción ética del príncipe, sino solo una descripción de los diversos factores que inciden en el origen y mantenimiento del gobierno de los distintos tipos de principado ${ }^{3}$. Por otra parte, Maurizio Viroli ha intentado mostrar que sí hay una concepción ética del príncipe en esta obra, mas no una que transforma radicalmente el ideal ético-político de aquella época, inspirado en Cicerón, sino que más bien lo adecúa a las circunstancias reales de la política ${ }^{4}$. Finalmente, para Isaiah Berlin, Maquiavelo no es ni amoral ni ciceroniano, pero tampoco un simple perverso. Según este análisis, el florentino habría presentado y contrapuesto dos ideales ético-políticos igualmente válidos, el cristiano y el maquiavélico, entre los cuales cualquier persona, incluido el príncipe, puede optar ${ }^{5}$.

A mi juicio, los textos avalan una lectura ética de El Príncipe que desmiente las tres interpretaciones recién mencionadas. Esta opinión general es compartida por varios estudiosos de Maquiavelo ${ }^{6}$. Con todo, y como intentaré mostrar, creo que muchos de ellos han presentado la concepción maquiavélica del buen príncipe sin destacar sus contornos con suficiente precisión, de modo que aparezca deslindada, por un lado, de los ideales ético-políticos de otros filósofos, y por otro, del ideal de gobernante republicano defendido en los Discursos sobre la primera década de Tito Livio.

A continuación, presentaré con más detalle las posiciones de Cassirer, Viroli y Berlin, para luego mostrar que ellas son poco convincentes. Junto con ello, quisiera argüir que el ideal ético-político del príncipe que defiende el florentino obedece a una concepción muy peculiar de este bien, a saber: se trata de un ideal que Maquiavelo llama "gran hombre», el cual debe ser realizado como fin último por aquellos pocos hombres que son impulsados por su humor al dominio y la opresión, y cuyas circunstancias y talentos naturales-en una palabra, su fortuna-les abren el camino del oficio de príncipe como único modo de satisfacción de ese impulso. Pero no es un ideal que deba ser realizado por

2 Véase Strauss, L., Thoughts on Machiavelli, Chicago University Press, Chicago, IL 1958, pp. 9-10; Lefort, C., Le travail de l'oeuvre machiavel, Gallimard, París 1986, pp. 73-92.

3 Véase Cassirer, E., The Myth of the State, Yale University Press, New Haven, CT 1946, caps. X-XII.

4 Véase Viroli, M., Machiavelli, Oxford University Press, Oxford 1998, pp. 50-56; «Introduction», en: Machiavelli, N., The Prince, trad. Bondanella, P., Oxford University Press, Oxford 2005, pp. xxxiii-xxxix.

5 Véase Berlin, I., «The Originality of Machiavelli», en: Berlin, I., Against the Current: Essays in the History of Ideas, ed. HARDY, H., The Viking Press, New York, NY 1980, pp. 74-75.

6 Véase, por ejemplo, Manent, P., «Politique de Machiavel», en: Manent, P., Enquête sur la démocratie, Gallimard, París 2007, pp. 294, 298-299; MANSFIELD, H. C., «Machiavelli's Virtue», en: Mansfield, H. C., Machiavelli's Virtue, Chicago University Press, Chicago, IL 1996, pp. 13-16; Chuaqu, T., "La ética política de Maquiavelo: gloria, poder y los usos del mal», reimpreso en: SAzo, D. (ed.), La revolución de Maquiavelo: El Príncipe 500 años después, Ril, Santiago 2013, pp. 165-200. 
el gobernante republicano ni por otras personas del principado o república. Dicho brevemente, es un ideal concebido como bien último obligatorio, no subordinado a ningún otro, pero restringido a aquellos hombres recién descritos.

\section{Tres interpretaciones: CAssirer, Viroli, Berlin}

Si bien el lector puede estar ya familiarizado con los análisis de Cassirer, Viroli y Berlin, de todos modos, es necesario revisar sus ideas principales, ya que esto permitirá, por contraste, poner de relieve con mayor exactitud la concepción maquiavélica del buen príncipe.

\subsection{Cassirer}

En su obra póstuma The Myth of the State, Ernst Cassirer se propuso, entre otras cosas, desengañarnos de la imagen común que tenemos de Maquiavelo. Pensamos en este filósofo como un hombre impío, inescrupuloso y promotor de los peores vicios y acciones que un político podría realizar. Mas este juicio yerra, según Cassirer, precisamente porque no se ha entendido el tipo de normatividad-o las condiciones de validez-de los imperativos maquiavélicos. La verdad, nos dice este autor, es que

[t]odos estos consejos son «imperativos hipotéticos», o para ponerlo en palabras de Kant, «imperativos de habilidad». [...] Maquiavelo estudió la acción política de la misma manera que un químico estudia reacciones químicas. [...] El Príncipe de Maquiavelo contiene muchas cosas peligrosas y venenosas, pero él las contempla con la frialdad e indiferencia de un científico. Él da sus prescripciones políticas. Por quién serán empleadas estas prescripciones y si acaso serán empleadas para un propósito bueno o malo, nada de eso le concierne. ${ }^{7}$

Como es obvio, Cassirer lee a Maquiavelo en términos de la clasificación kantiana de las condiciones de validez de los imperativos. Los imperativos maquiavélicos serían imperativos de habilidad, es decir, tienen la forma «necesariamente, si se quiere realizar $a$, entonces debe hacerse $b$ ». Estos imperativos son válidos para evaluar la corrección de las acciones de un agente bajo dos condiciones: primero, que el agente adopte $a$ como fin; y segundo, que efectivamente haya una vinculación causal necesaria entre $b$ (causa) y $a$ (efecto) ${ }^{8}$.

Para entender la lectura de Cassirer, hay que notar que, como muestra la forma de los imperativos de habilidad, la necesidad no recae sobre la adopción del fin, sino sobre la realización de los medios para lograrlo. La adopción del fin es arbitraria; no hay ninguna obligación, ni para el príncipe ni para ninguna otra persona, de adoptarlo: «[a]quí no se trata en absoluto de si acaso el fin es

7 CASSIRER, E., The Myth of the State, p. 154.

8 Véase Kant, I., Grundlegung zur Metaphysik der Sitten, ed. B. Kraft y D. Schönecker, Meiner, Hamburgo 1999, AA IV 413-415. 
racional y bueno, sino solo de lo que uno tiene que hacer para alcanzarlo» ${ }^{9}$. Por eso, Cassirer dice que Maquiavelo estudia la política como un químico, esto es, estableciendo la necesidad de las relaciones causales entre ciertos medios y un determinado fin, a saber, el de la obtención y mantención del poder que culmina en la gloria del príncipe. Las reflexiones de Maquiavelo se reducirían a un ejercicio de racionalidad teórico-causal (instrumental); no determinarían en absoluto cuáles son los bienes que un príncipe debe o le es lícito perseguir, y por ende carecerían de todo contenido propiamente ético. La impresión común-casi diabólica—que tenemos de Maquiavelo sería, en consecuencia, un craso error.

\subsection{Viroli}

Maurizio Viroli ha intentado mostrar que la condena moral a Maquiavelo, así como la frialdad científica atribuida a él por Cassirer, son corregibles mediante una lectura atenta de los pasajes ${ }^{10}$. Para este autor, en El Príncipe Maquiavelo se propone ofrecer una rectificación, no una subversión, de las doctrinas ciceronianas del buen político y de las acciones requeridas para llegar a serlo: «[a]unque radical, la crítica de Maquiavelo a la tradición ciceroniana y a la concepción de la política como sabiduría civil intenta restringir la extensión de su validez, más que rechazarla completamente» ${ }^{11}$. Viroli resume su lectura con las siguientes palabras:

Para poner el argumento de Maquiavelo en una sola oración: en la medida que un príncipe o gobernante pueda («potendo»), no debe «desviarse de la recta conducta», pero tiene que «ser capaz de entrar en el camino del mal actuar, si es forzado a ello por necesidad», o para traducir mejor sus palabras, «necesitado» («necessitato»). [...] Tan pronto como un dominio se consolida, las crueldades y los poderes absolutos han de ser reemplazados por la justicia civil ordinaria y la razón, como prescribe la tradición de la sabiduría civil; pero antes de que rija el derecho, la política en el sentido convencional del arte de gobernar de acuerdo con la razón y la justicia, requiere la ayuda del ambivalente pero poderoso arte del estado. ${ }^{12}$

Si bien Maquiavelo estaría de acuerdo con Cicerón en cuanto al ideal del buen príncipe, él habría visto que hay circunstancias políticas difíciles, especialmente aquellas que informan la fundación y consolidación de un dominio, que hacen necesarias acciones diferentes y aparentemente opuestas a las que son reconocidas como buenas en la concepción moral y política clásica ${ }^{13}$. Solo

9 KANT, I., Grundlegung zur Metaphysik der Sitten, AA IV 415.

10 Véase Viroli, M., Machiavelli, p. 54; «Introduction», p. xxxiii.

11 Viroli, M., Machiavelli, p. 54.

12 VIROLI, M., Machiavelli, pp. 55-56.

13 La tesis de que el objeto propio de Maquiavelo en El Príncipe es el nuevo principado, y que por ende sus preceptos se restringen al nuevo (aún por legitimarse ante sus súbditos) príncipe, es desarrollada en detalle por Poсоск, J. G. A., The Machiavellian Moment: Florentine Political Thought and the Atlantic Republican Tradition, Princeton University Press, Princeton, NJ 1975, cap. 6. 
en esos contextos difíciles serían válidos los preceptos controversiales de Maquiavelo, cuya validez se basaría, por tanto, en que las acciones que prescriben son las únicas que hacen posible la realización del ideal ciceroniano del buen príncipe y de un gobierno conforme a la razón y al derecho, esto es, justo.

Más aún, Cicerón parecería haber afirmado algo similar:

[E]n caso de que, para tu provecho, hubieres quitado a un hombre algo que no sirve para nada, te habrás portado inhumanamente y en contra de la ley natural. Si, por el contrario, eres tal que puedes ocasionar un gran provecho a la república y a la sociedad humana si quedas con vida, no debe censurarse el que por esa razón hayas quitado algo a otro. ${ }^{14}$

La originalidad de Maquiavelo estribaría en el reconocimiento de más circunstancias políticas en las que se requiere, en pos de la justicia, actuar drásticamente contra otros.

En suma, Viroli supone que para Maquiavelo el desempeño violento del cargo de príncipe es parte integral—dadas las circunstancias de nuestra vida políticade la realización de los bienes de la justicia y el buen gobierno. Nótese, empero, que para Cicerón la justicia y el buen gobierno son bienes por sí mismos, no subordinados a otros, y que además deben ser adoptados como fines por toda persona $^{15}$. Si Maquiavelo es ciceroniano, entonces se habría representado el ideal del buen príncipe bajo normas éticas generales de justicia y gobierno, obligatorias para toda persona que pertenece a una comunidad política, al margen de sus preferencias, anhelos o temores particulares. Dicho de otro modo, habría concebido al príncipe ideal según las exigencias de una única moral universalmente válida.

\subsection{Berlin}

Tras una larga revisión de múltiples interpretaciones del pensamiento de Maquiavelo, Isaiah Berlin, insatisfecho con lo que se había dicho hasta ese momento (el año 1972), pretende resolver la siguiente cuestión: en qué sentido se justifican las medidas que recomienda Maquiavelo a los gobernantes ${ }^{16}$. En la respuesta a esta pregunta se hallaría-cree Berlin-la originalidad del pensamiento maquiavélico.

La justificación vendría dada por la forma en que Maquiavelo concibió la ética. Según Berlin, el florentino entendió y aceptó «la posibilidad de más de un sistema de valores, sin que haya ningún criterio común a los sistemas mediante el cual se pueda hacer una elección racional entre ellos» ${ }^{17}$. En concreto, Maquiavelo habría presentado y contrapuesto dos sistemas de valores: el cristiano y el suyo propio $^{18}$. Pero esto no quiere decir que haya bosquejado ambos sis-

14 Cicerón, M. T., De los deberes, ed., trad. y notas de B. Estrada Morán, Universidad Autónoma de México, México D.F. 1948, III.6.4.

15 Véase los textos citados más abajo, sección 2.2.

16 Véase BerLin, I., «The Originality of Machiavelli», p. 44.

17 BERLIN, I., «The Originality of Machiavelli», p. 71.

18 Véase BerLin, I., «The Originality of Machiavelli», p. 54. 
temas, así como la imposibilidad de decidir entre ellos mediante un valor más alto, mientras permanecía neutral entre ellos. Berlin no piensa, como Cassirer, que Maquiavelo sea un frío e indiferente científico. Pero tampoco comparte la posición de Viroli, que inserta las doctrinas maquiavélicas en una moral universal única de carácter ciceroniano y cristiano. Por el contrario, Berlin cree que Maquiavelo habría afirmado la validez de ambos sistemas, de modo que su pensamiento efectivamente poseería contenido ético ${ }^{19}$, pero al mismo tiempo habría mostrado claramente su opción por un sistema-el suyo propio-que difiere radicalmente de la moral cristiana y ciceroniana ${ }^{20}$.

En consecuencia, Maquiavelo no habría pensado su ideal del buen príncipe como un fin último obligatorio para nadie, sino solo como un modelo por el cual es legítimo optar.

La interpretación de Berlin, empero, no concluye aquí. En primer lugar, debe notarse que, para este comentador, el ideal del buen príncipe y el del buen gobernante republicano son uno y el mismo:

Pero cualesquiera que fueran las disparidades [entre El Príncipe y los Discursos], la corriente central que pasa a través de ambos es una y la misma. La visión-el sueño-típica de muchos escritores que se ven a sí mismos como realistas inflexibles-de la patria fuerte, unida, efectiva, moralmente regenerada, espléndida y victoriosa, ya sea salvada por la virtù de un hombre o de muchos-permanece central y constante. [...] Pero los valores básicos, el fin último-la visión beatífica de Maquiavelo-no varía. ${ }^{21}$

Esta identificación entre el fin último del príncipe y el del jefe republicano tiene su raíz última, a mi juicio, en que el ideal ético-político de El Príncipe es, para Berlin, un ideal por el que puede optar todo ser humano, y que por ende es universal: «La idea moral para la que [Maquiavelo] cree que no hay sacrificio demasiado grande-el bienestar de la patria —es para él la forma más alta de la existencia social alcanzable por el hombre» ${ }^{22}$. De hecho, Berlin puede contraponer, tout court, el ideal maquiavélico con el cristiano precisamente porque él cree que el primero es tan universal como el segundo.

En consecuencia, Berlin entiende la concepción maquiavélica del buen príncipe bajo un sistema de valores que no es obligatorio para nadie, pero por el que es válido optar. Además, es un sistema de valores universal, legítimo para todo ser humano, no solo para quienes tienen el cargo de príncipe.

Como se dijo en la introducción, creo que los textos sugieren un cuadro muy diferente de aquellos presentados por Cassirer, Viroli y Berlin. Ahora que las posiciones de estos autores están claras, podemos revisar los textos teniendo sus puntos principales en mente, para así formarnos poco a poco, por contraste, una posición distinta y al mismo tiempo basada en las palabras del mismo Maquiavelo.

19 Véase Berlin, I., «The Originality of Machiavelli», pp. 46, 52-53.

20 Véase Berlin, I., «The Originality of Machiavelli», pp. 54-55.

21 BerLin, I., «The Originality of Machiavelli», p. 56.

22 Berlin, I., «The Originality of Machiavelli», p. 57 (énfasis mío). 


\section{EXPOSICIÓN E INTERPRETACIÓN DE LOS TEXTOS}

No es inusual que grandes autores-Anselmo, Descartes, Kant-den importantes claves para la interpretación de sus escritos en el prefacio. Lo que parece un añadido insustancial, casi un ornamento, anticipa y contiene en realidad algunas de las ideas y propósitos principales de la obra. Como observó Leo Strauss, El Príncipe no es una excepción ${ }^{23}$. En la Carta Dedicatoria hallamos de hecho los ejes en torno a los cuales podemos determinar si acaso Maquiavelo tiene una concepción del buen príncipe, y en caso de tenerla, en qué consiste. Tanto es así, que en la Carta Dedicatoria se encuentran, como en potencia y mutua tensión, las tres lecturas que revisamos anteriormente, así como la que propondremos en esta sección.

Maquiavelo dice que ofrece como regalo «el conocimiento de las acciones de los grandes hombres, aprendido mediante una larga experiencia de las cosas modernas y de una continuada lectura de las antiguas ${ }^{24}$. La obra en la que ese conocimiento se expone es un medio para "comprender todo cuanto yo, en tantos años y con tantas incomodidades y peligros, he conocido y entendido $»^{25}$. Más aún, el autor ha osado «discurrir y dar reglas sobre el gobierno de los príncipes ${ }^{26}$.

Estos pasajes debieran hacernos preguntar al menos tres cosas. En primer lugar, ¿qué hace "grandes» a esos hombres (Teseo, Filopemen, Moisés)? ¿No es acaso el adjetivo "grande» un término valorativo, de modo que Maquiavelo alaba a estos hombres y piensa en sus cualidades como en un ideal ético para el príncipe? Segundo, si lo que Maquiavelo expone en su libro es todo lo que ha llegado a entender, mas no hay en esa obra ningún tratamiento del gobierno conforme a la «justicia civil ordinaria y la razón», tal como lo prescribiría la tradición de la sabiduría civil, ¿no debemos entonces pensar que Maquiavelo concibió su propio ideal como una alternativa al de la tradición de la sabiduría civil, y no en continuidad con este último? Y si es una alternativa, ¿la entendió como la única válida? Tercero, Maquiavelo pretende establecer reglas para el gobierno de los príncipes. ¿Son esas reglas, o al menos algunas de ellas, prescripciones para llegar a ser y permanecer siendo un gran hombre? ¿Se restringen ellas al gobierno de los príncipes, quizás solo a algunos hombres, o aparecen subsumidas bajo un ideal ético universal?

Las tres lecturas revisadas son diferentes respuestas a estas preguntas. La decisión de la disputa entre ellas debe hacerse mediante la exposición y comentario de aquellos pasajes de El Príncipe que nos muestran las respuestas correctas. Primero, atenderé a las preguntas sobre los grandes hombres, donde ya se tendrá elementos para rechazar la posición de Cassirer. Luego revisaré la cues-

23 Véase Strauss, L., Thoughts on Machiavelli, pp. 15-24.

24 Maquiavelo, N., El Príncipe, ed. G. Inglese, trad. y notas H. Puigdoménech, Tecnos, Madrid 2011, p. 5 (énfasis mío).

25 Maquiavelo, N., El Príncipe, p. 5 (énfasis mío).

26 Maquiavelo, N., El Príncipe, p. 5 (énfasis mío). 
tión del alcance y los límites de la aplicación de los preceptos maquiavélicos. Los pasajes que revisaremos sugieren un cuadro muy diferente del presentado por Viroli. Finalmente, basado en los análisis previos, intentaré mostrar cuáles son las condiciones de validez del ideal maquiavélico del gran hombre o buen príncipe, las cuales, a mi juicio, no calzan con la posición de Berlin.

\subsection{Los grandes hombres}

Al leer los capítulos 2 y 3 , en los que Maquiavelo propiamente comienza a tratar el gobierno de los principados, pareciera que la expresión «grandes hombres» no tiene un sentido ético. Al inicio del capítulo 2, él dice que «discutir[á] cómo estos principados [sc. los mencionados en el capítulo 1] se pueden gobernar y conservar ${ }^{27}$, sin mencionar nada sobre el gobierno justo, ni sobre la manera moralmente correcta de mantenerse en el poder. Luego, en el capítulo 3 , discute las acciones necesarias para hacerse del poder y mantenerlo en los principados mixtos, mas con un lenguaje purificado de términos éticos:

Quien adquiera territorios nuevos de este tipo y quiera retenerlos ha de tener en cuenta, pues, dos cosas: una, que la sangre del antiguo príncipe se extinga; otra, que no hay que alterar ni las leyes ni los impuestos; de tal manera que en poco tiempo se convierta, uniéndose con el principado antiguo, en un solo cuerpo. ${ }^{28}$

Lo que aparentemente tenemos aquí no es más que un imperativo de habilidad, un caso de racionalidad instrumental: necesariamente, si se quiere $a$, entonces hágase $b$.

Posteriormente, al discutir sobre la conservación del poder en regiones donde no se habla el mismo idioma, Maquiavelo parece prescribir de la misma manera:

Uno de los mejores y más eficaces remedios sería que la persona que los adquiera [sc. los territorios de habla diferente] fuera a vivir allí. [...] Otro gran remedio es el establecimiento de colonias en uno o dos sitios, que sean como cepos de este estado [...]. Con las colonias no se gasta mucho; y sin gastos, o pocos, se mantiene este territorio, y se ofende tan solo a los que se les quitan los campos y casas para darlos a los nuevos habitantes, que no pasan de ser una mínima parte de este Estado. ${ }^{29}$

La misma racionalidad instrumental aparece en otros preceptos, y si bien el florentino llama «sabios» a los romanos, y «prudentes» a quienes actúan como ellos, la razón estriba en que correctamente adecúan las acciones a su fin (la mantención del poder), sin que este último sea juzgado éticamente por

27 Maquiavelo, N., El Príncipe, cap. 2, p. 11.

28 Maquiavelo, N., El Príncipe, cap. 3, p. 17.

29 Maquiavelo, N., El Príncipe, cap. 3, pp. 17, 19. 
Maquiavelo ${ }^{30}$. Asimismo, cuando habla de «error» y «censura» en relación con los actos de Luis, rey de Francia, a lo único que se refiere es a la inadecuación entre los medios elegidos por él y el objetivo que se había propuesto:

El deseo de adquirir es, verdaderamente, algo muy natural y ordinario; y siempre que este deseo lo actúen hombres que tienen a su favor todas las posibilidades, serán alabados y nunca censurados; pero, por el contrario, cuando no pudiendo se empeñan en hacerlo, caen en el error y se les censura justamente. ${ }^{31}$

Así, Cassirer parece haber dado en el clavo. Pero si avanzamos en la lectura de El Príncipe, nos desengañamos de esta apariencia. En el capítulo 6, Maquiavelo esboza brevemente su método para establecer preceptos, así como la justificación del mismo. El método consiste en analizar cuidadosamente las acciones de los gobernantes del pasado y del presente, para reconocer a aquellos que han sido grandes hombres, de cuyas acciones pueden desprenderse preceptos o reglas para el gobierno. La justificación reside en que los hombres casi siempre toman decisiones y siguen cursos de acción de acuerdo con el ejemplo de otros, pasados o presentes ${ }^{32}$.

Podría pensarse que aquellos grandes hombres son meramente los que adquirieron y conservaron el poder, incluso que lograron expandirlo, de modo que, al ponerlos como ejemplos, Maquiavelo permanecería situado en el campo de los imperativos de habilidad. La noción de gran hombre tendría un contenido descriptivo ajeno a evaluaciones éticas. Decir «necesariamente, si se quiere ser un gran hombre, entonces hágase $b$ » equivaldría a «necesariamente, si se quiere adquirir el poder político y conservarlo, entonces hágase $b$ ».

Pero es claro que no es así, pues ello implicaría que Maquiavelo se abstuvo de formular valoraciones propias respecto de los fines de los gobernantes que él menciona, analiza y discute. Respecto del papa Julio, dice:

Y todo eso Julio no solo lo continuó, sino que aún fue más allá; y decidió ganarse Bolonia, aniquilar a los venecianos y expulsar a los franceses de Italia; empresas todas de las que salió victorioso y con tanta más gloria para él cuanto que todo lo hizo para aumentar el poder de la Iglesia y no el de un particular. ${ }^{33}$

Esta no es una mera valoración de los medios por su adecuación para lograr un determinado fin, sino del fin mismo de los actos de Julio. La idea del gran hombre, en consecuencia, pertenece a la ética; se trata de un ideal al que los príncipes debieran conformarse.

El problema que aparece ahora es: ¿qué hace grande a un hombre? La respuesta se halla en el capítulo 6, donde se listan sus atributos:

30 Véase Maquiavelo, N., El Príncipe, cap. 3, pp. 23, 25: «Porque los romanos hicieron, en estos casos, lo que todos los príncipes sabios deben hacer [...]. [P]refirieron, en cambio, seguir los dictados de su virtud y prudencia».

31 Maquiavelo, N., El Príncipe, cap. 3, p. 29.

32 Véase Maquiavelo, N., El Príncipe, cap. 6, p. 49; cap. 14, p. 143.

33 Maquiavelo, N., El Príncipe, cap. 11, p. 109. 
Pero estos hombres hallan muchas dificultades a la hora de actuar, y su camino está sembrado de peligros y conviene que con gran virtud los superen; pero una vez superados estos, y cuando empiezan a ser objeto de veneración, habiendo destruido a todos cuantos podían envidiar sus cualidades, se mantienen poderosos, seguros, honrados y felices. ${ }^{34}$

Los cuatro últimos adjetivos son los atributos que conforman el ideal del príncipe, y son presentados-todos o algunos-en cada uno de los ejemplos de gobernantes que Maquiavelo llama a imitar. Hasta donde puedo ver, nunca, a lo largo de todo El Príncipe, los rechaza o recomienda otros. La obtención del poder y su conservación eran las razones por las cuales llamó, como vimos antes, «sabios» a los romanos y «prudentes» a quienes los imitan. Luego, en el capítulo 13, Maquiavelo rechaza el uso de tropas auxiliares, e insiste en la conformación de tropas propias. Las razones, nuevamente, son el poder y la seguridad de su conservación, mas también la reputación honrosa y la gloria, como se destaca en el caso de César Borja ${ }^{35}$. Los consejos respecto de la liberalidad y parsimonia en los gastos tienen como criterio común esto último: «Y por sobre todas las cosas, un príncipe debe resguardarse de ser despreciado y odiado ${ }^{36}$. Asimismo, la insistencia en no depender de otros ni de la fortuna deriva del atributo de la seguridad en la mantención del poder ${ }^{37}$.

Más aún, en la sección final de la obra, que ciertamente ha sido objeto de diversas interpretaciones, nuevamente se invoca este ideal: «¿Qué puertas se le cerrarían? ¿Qué pueblos le negarían obediencia? ¿Qué envidia se le opondría? ¿Qué italiano le negaría su homenaje?» ${ }^{38}$. Estas preguntas retóricas elevan a la más alta estima la ascensión al poder, el mantenimiento y seguridad del mismo, los honores y la gloria. En otras palabras, elevan a ideal ético-pace Cassirerla concepción maquiavélica del gran hombre.

No debe perderse de vista que hay cuatro atributos que conforman el ideal del gran hombre. Es insuficiente decir-como hace Tomás Chuaqui, siguiendo a Hannah Arendt y Quentin Skinner-que el fin último que Maquiavelo propone es la gloria ${ }^{39}$. El gran hombre no consigue gloria sin más, sino la gloria que sobreviene específicamente a quien alcanza y mantiene el poder sobre un dominio. Tampoco basta con afirmar-como en el caso de Pierre Manent y Harvey Mansfield-que el fin de los seres humanos es la adquisición ${ }^{40}$. El gran hombre no es solo el que adquiere y conserva el poder político, sino quien además recibe

34 Maquiavelo, N., El Príncipe, cap. 6, p. 55.

35 Véase Maquiavelo, N., El Príncipe, cap. 13, pp. 127-135; cap. 14, p. 139: «Estar desarmado te hace despreciable».

36 Maquiavelo, N., El Príncipe, cap. 13, pp. 127-135.

37 Véase Maquiavelo, N., El Príncipe, cap. 6, pp. 55-57; cap. 9, p. 97; cap. 14, pp. 139-143; cap. 25, pp. 247-255.

38 N. Maquiavelo, El Príncipe, cap. 26, p. 265.

39 Véase Chuaqu, T., «La ética política de Maquiavelo: gloria, poder y los usos del mal», p. 166 n.2.

40 Véase Manent, P., «Politique de Machiavel», p. 294; Mansfield, H. C., «Machiavelli’s Virtue», p. 13. 
honores y gloria por su ejercicio. Ciertamente, para Maquiavelo lo primero conduce siempre a lo segundo: «en las acciones de todos los hombres, especialmente de los príncipes, donde no hay tribunal al que apelar, se atiende al resultado. Procure pues el príncipe ganar y mantener el estado: los medios serán siempre juzgados honorables y alabados por todos ${ }^{41}$. No obstante, importa hacer la distinción, al menos conceptual, entre mantención del poder y consecución de la gloria, para así entender el ideal maquiavélico en sus diversos matices.

Recientemente, Daniel Mansuy se ha manifestado contra la tesis de que Maquiavelo presenta un ideal ético. Hablando de los Discursos sobre la primera década de Tito Livio, afirma: "Imitar a los romanos implica seguir de modo implacable la regla de la acción política, esto es, someterse plenamente al reino de la necesidad-que no es el reino de la moral ni de la religión ${ }^{42}$. La razón detrás de tal aseveración es que «la vida política es movimiento constante, los asuntos humanos no están nunca en reposo», de modo que «no hay programa político que sea determinable en abstracto» ${ }^{43}$.

Creo que estas afirmaciones obedecen a una confusión. El mismo Mansuy dice que Maquiavelo aboga por la imitación de Roma, y que esta última quería ser grande y gloriosa ${ }^{44}$. He aquí, pues, la determinación abstracta del fin que debe adoptar la república, así como el príncipe, lo cual es compatible con el incesante movimiento de los asuntos humanos y la consiguiente incapacidad de determinar en abstracto los medios para alcanzar ese fin. Más aún, Maquiavelo no podría entender como móvil el reino de los medios, es decir, la conducta que debe adoptar un gobernante, si no fuera porque ve un fin determinado como inmóvil. Primero, porque no se puede entender nada como variable a no ser por referencia a algo invariable (sea del tipo que fuere). Segundo, porque ciertos medios $m$ son tales solo por referencia a un fin determinado $f$. Por tanto, los medios $m$ como tales solo pueden entenderse como variables en la medida en que sean referidos al fin $f$ concebido como invariable. La fluctuación del reino de los medios depende de la fijeza del reino de los fines.

Por otra parte, tampoco debe contraponerse la necesidad y la moral (o religión). La noción de fin en ningún caso incluye que el fin sea opcional. De aquí

41 Maquiavelo, N., El Príncipe, cap. 18, pp. 173-175. Dicho sea de paso, este pasaje corrige una afirmación anterior del cap. 8, p. 81: «si se considera la virtud de Agatocles al arrostrar y vencer los peligros, y su grandeza de ánimo a la hora de soportar y superar las adversidades, no se ve por qué se le deba juzgar inferior a cualquier otro excelentísimo capitán; pero en cambio su feroz e inhumana crueldad, así como sus innumerables maldades no consienten que sea celebrado entre los hombres más excelentes». La clara contradicción entre las afirmaciones del cap. 18 y las del cap. 8 dan pie para pensar que El Príncipe no debe leerse como si Maquiavelo, en cada una de sus partes, expusiera los resultados finales de su pensamiento; por el contrario, quizá habría que leer la obra como un pensamiento en desarrollo, y por ende susceptible de correcciones, matices y añadidos sustanciales a medida que avanza.

42 Mansuy, D., "Maquiavelo y la república: notas críticas», en: SAzo, D. (ed.), La revolución de Maquiavelo: El Príncipe 500 años después, Ril, Santiago 2013, p. 113.

43 Mansuy, D., "Maquiavelo y la república: notas críticas», pp. 110-111.

44 Véase Mansuy, D., «Maquiavelo y la república: notas críticas», pp. 108-109. 
que Tomás de Aquino, por ejemplo, hable de fines necesarios o naturales, así como de fines contingentes ${ }^{45}$. Si el ideal maquiavélico del príncipe, en último término, se presenta como un fin último necesario al menos para ciertos hombres, y por ende como el único válido para ellos, no por eso es un ideal extraño al ámbito de la ética.

Finalmente, Mansuy destaca que el príncipe maquiavélico ha de poseer un carácter plástico, esto es, despojado de hábitos que constriñen e incluso inhiben la acción eficaz bajo ciertas circunstancias. Pero esta plasticidad puede ser entendida como buena solo en la medida en que sea referida a un criterio de bondad, un objetivo que constituya la meta estable del príncipe. Esta, como se vio, no es otra que la de convertirse en un gran hombre.

\subsection{La justicia y el príncipe maquiavélico}

De acuerdo con lo anterior, Maquiavelo presentó un ideal ético para el príncipe, el cual consiste en cuatro atributos principales: posesión del poder, seguridad en el mismo, honores o gloria y, finalmente, felicidad. Con todo, cabe aún preguntarse si acaso este ideal ha de ser la meta última de todo príncipe a lo largo de su gobierno, o si es más bien válido solo bajo otro ideal y por tanto solo en algunas circunstancias. Conforme a lo primero, el ideal sería válido universal e incondicionalmente para el príncipe; conforme a lo segundo, en cambio, su validez sería acotada y condicionada.

Como se vio, Viroli interpreta los preceptos maquiavélicos de esta última manera. Las circunstancias bajo las cuales tendrían validez serían aquellas que obligan a un gobierno, so pena de colapso, a seguir esos preceptos. Por otra parte, el ideal al que estos últimos estarían subordinados sería el del gobierno justo, tal como lo entendieron Cicerón y otros autores clásicos y cristianos.

Esta lectura, sin embargo, enfrenta una grave dificultad, incluso al margen del análisis detallado de El Príncipe, pues Viroli presenta una doctrina incoherente. Para Cicerón, la justicia consiste en que a nadie se le cause daño y en que se sirva a la común utilidad, de tal manera que se mire por el bien de todo ser humano, quienquiera que este sea, por la sola razón de que es humano ${ }^{46}$. Ahora bien, Maquiavelo abiertamente declara injustos, desde la perspectiva ciceroniana, algunos de los actos que él prescribe. Por tanto, si hubiese pensado esos actos como parte necesaria del proceso de realización del gobierno justo, tendría que haber concebido tal gobierno como justo para unos, pero injusto para otros. Por ejemplo, no será justo con aquellos pobladores cuyas pertenencias les fueron despojadas para el establecimiento de colonias, ni con esos niños asesinados que eran hijos o parientes del príncipe cuyo dominio ha sido conquistado. ¿Cómo podría la realización de la justicia ciceroniana, o del gobierno justo, legitimar la comisión de tales actos injustos? La única defensa posible

45 Véase Tomás de Aquino, Quaestiones disputatae de veritate, q. 24, a. 1, ad 18, en Quaestiones disputatae, ed. SPIAzzi, R., vol. 1, Marietti, Turín 1964.

46 Véase Cicerón, M. T., De los deberes, I.10.1; III.6.1. 
tendría que proveerla algún ideal más alto que la justicia, al cual esta última esté subordinada. Sin embargo, tal subordinación es expresamente condenada por el mismo Cicerón:

Pero esa elevación de alma que se muestra en los peligros y en los trabajos incurre en falta si está desprovista de justicia. ${ }^{47}$

Así pues, quien se proponga alcanzar la verdadera gloria, cumpla con los deberes de la justicia. ${ }^{48}$

[T] odos estamos comprendidos dentro de una sola e idéntica ley natural, y por tanto está prohibido ofender a otro. ${ }^{49}$

Es cierto que, como dice Cicerón en el texto citado en la sección 1.2., una persona que es de gran provecho para la república puede, en pos de esta última, apropiarse algo ajeno. Mas de lo que se trata allí es de tomar algo para permanecer con vida; es un caso extremo de subsistencia, en el que se considera quitar a otro, por ejemplo, un trozo de pan, no despojarle de su casa y otros bienes necesarios, ni mucho menos hacerle un grave daño físico. Sin duda, Maquiavelo también excusa las acciones injustas que él prescribe aduciendo necesidad: «De donde le es necesario al príncipe que quiera seguir siéndolo aprender a poder no ser bueno y utilizar o no este conocimiento según la necesidad ${ }^{50}$. Pero esto no lo hace equiparable a Cicerón: la necesidad que contempla este último se basa en la subsistencia humana; la que observa Maquiavelo, en cambio, radica en la subsistencia en el poder, la recepción de honores y la conquista de la gloria. (Bien puede un líder político sobrevivir a la pérdida del poder, como fue el caso de Piero Soderini).

En consecuencia, si Maquiavelo solo hubiese querido rectificar las ideas de Cicerón, en realidad las habría transformado de raíz, al punto de volverlas inconsistentes. Quien no quiera hacer de El Príncipe un absurdo, debe buscar una lectura alternativa a la de Viroli ${ }^{51}$.

Este comentador, con todo, no ha presentado su posición sin hacer un análisis pormenorizado de algunos pasajes. El texto clave, a su juicio, parece ser uno del capítulo 18, donde Maquiavelo habla en términos generales sobre lo que debe hacer un príncipe:

47 Cicerón, M. T., De los deberes, I.19.1.

48 Cicerón, M. T., De los deberes, II.13.1.

49 Cicerón, M. T., De los deberes, III.6.1.

50 Maquiavelo, N., El Príncipe, cap. 15, p. 147.

51 Lo dicho revela asimismo el error de Wood, N., Cicero's Social and Political Thought, University of California Press, Berkeley/Los Ángeles, CA 1988, pp. 176-177: «Cicerón, no menos que Maquiavelo, se presenta como un frío realista, versado en las dificultades del poder, las complejidades de la manipulación y los usos de la violencia. [...] Él es un maestro del arte político que habría tenido poco que aprender de Maquiavelo sobre la adquisición, la conservación y el aumento del poder». La justificación ciceroniana de las manipulaciones y la violencia (por ejemplo, el asesinato de un tirano) viene dada por el valor mismo de la justicia: «quien no impida la injuria ni se opone a ella, pudiendo hacerlo, incurre en la misma culpa que si abandonara a sus padres o a sus amigos o a su patria» (De los deberes, I.7.4). Maquiavelo, en cambio, no adhiere en el contexto político a la justicia como criterio último de legitimidad de las acciones. 
Y hay que tener bien en cuenta que el príncipe, y máxime uno nuevo, no puede observar todo lo que hace que los hombres sean tenidos por buenos, ya que a menudo se ve forzado para conservar el estado a obrar contra la fe, contra la caridad, contra la humanidad, contra la religión. Por eso tiene que contar con un ánimo dispuesto a moverse según los vientos de la fortuna y la variación de las cosas se lo exijan, y como ya dije antes, no alejarse del bien, si es posible, pero sabiendo entrar en el mal si es necesario. ${ }^{52}$

Aquí se aprecia un claro énfasis en el nuevo príncipe y sus circunstancias, de modo que la validez de los preceptos maquiavélicos podría entenderse como restringida a ellas ( $u$ otras que hicieren igualmente difícil el gobierno). De modo similar, Maquiavelo había dicho, en el capítulo 17, que «entre todos los príncipes es el nuevo al que le es imposible rehuir la fama de cruel, porque el estado nuevo está lleno de peligros ${ }^{53}$.

Pero si comparamos este pasaje con otros, veremos de inmediato que las palabras condicionales de Maquiavelo «entrar en el mal si es necesario» no aluden a situaciones exclusivas de los comienzos del gobierno de un principado. De hecho, el capítulo 19 dice:

Y aquí se debe señalar que el odio se gana tanto con las buenas como con las malas obras; así que, como ya dije antes, un príncipe que quiera mantener su estado se ve a menudo forzado a no ser bueno; porque, cuando aquella colectividad, ya sean pueblos, soldados o grandes señores que tú juzgues necesitar para mantenerte esté corrompida, te conviene seguir su humor para satisfacerla; con lo que entonces las buenas obras son tus enemigas. ${ }^{54}$

Maquiavelo afirma que el príncipe «se ve a menudo forzado a no ser bueno», sin restringir esta declaración a quien es nuevo en el cargo. Pero lo más notable de este texto es la razón que obliga al príncipe a adentrarse en el mal, a saber, la necesidad de obtener el apoyo de un grupo de gente corrompida (como los pretorianos, cuando Pertinax ascendió al poder). Esta razón debe hacernos pensar que todo príncipe, a menudo o constantemente, tiene y tendrá que adentrarse en el mal, pues «de los hombres, en general, se puede decir esto: que son ingratos, volubles, hipócritas, falsos, temerosos del peligro y ávidos de ganancias» ${ }^{55}$, «los hombres», dice el florentino, «siempre te saldrán malos, a menos que la necesidad los haga buenos ${ }^{56}$. En definitiva, «los hombres son malos ${ }^{57}$. La corrupción es generalizada, una característica propia de la condición humana, de modo que el actuar de un príncipe maquiavélico constantemente tendrá que incurrir en lo que un ciceroniano cree que es el mal ${ }^{58}$. El príncipe ideal de Maquiavelo

52 Maquiavelo, N., El Príncipe, cap. 18, p. 173.

53 Maquiavelo, N., El Príncipe, cap. 17, p. 159.

54 Maquiavelo, N., El Príncipe, cap. 19, pp. 189-191.

55 Maquiavelo, N., El Príncipe, cap. 17, p. 159.

56 Maquiavelo, N., El Príncipe, cap. 23, p. 239.

57 Maquiavelo, N., El Príncipe, cap. 18, p. 171.

58 Véase Maquiavelo, N., El Príncipe, cap. 15, p. 147: «no se pueden tener todas [sc. la generosidad, la misericordia, la fidelidad, etc.] ni observarlas plenamente, ya que las condiciones humanas no lo permiten». 
conjuga disposiciones para hacer lo que Cicerón considera bueno pero también lo que considera malo: «es necesario que un príncipe sepa actuar según convenga, como bestia o como hombre [i.e. con la fuerza o con las leyes]» ${ }^{59}$.

Más aún, como ha destacado Harvey Mansfield, el príncipe maquiavélico es un versado hombre de apariencias ${ }^{60}$. No solo debe ser virtuoso en el sentido de albergar tanto la bestialidad como la humanidad en sí mismo, sino que debe emplear ambas características para que sus súbditos le teman reverencialmente-como a un dios. La virtù maquiavélica es, ante todo, una exhibición del príncipe ante sus súbditos que provoque temor reverencial. En efecto, para Maquiavelo un príncipe debe principalmente ocuparse de la guerra y sus ejér$\operatorname{citos}^{61}$. Pero «sin esta fama [de cruel]», continúa Maquiavelo, «no se mantiene nunca un ejército unido ni dispuesto a acción alguna ${ }^{62}$. Y esa fama no se restringe a los ejércitos. Como es claro en la narración de los actos de César Borja para pacificar la Romaña, el príncipe también debe infundir en el pueblo la expectativa de crueldad y traición, de poder implacable e inapelable, para que cuando él actúe, la mayoría sienta alivio y agradecimiento por sus acciones-ya sea porque dañan solo a algunos, ya sea porque satisfacen el deseo de venganza del pueblo que ha sido maltratado ${ }^{63}$.

Este acento en la apariencia del gran hombre, que lo hace dependiente del juicio de los demás, no podría estar más lejos de los ideales cristiano y estoico del hombre virtuoso ${ }^{64}$. Asimismo, el acento en la bestialidad se opone al santo cristiano, que está llamado a «soportar, no a hacer, actos de fuerza» y que pone «el mayor bien en la humildad, abyección y el desprecio de las cosas humanas $»^{65}$. El ideal maquiavélico, por tanto, difiere radicalmente de la «justicia civil ordinaria y la razón» a la que adhiere la tradición de la sabiduría civil en que Viroli quiere situar a Maquiavelo.

Los pasajes que hemos visto sugieren, además, que el ideal del gran hombre, por lo que tiene de bestialidad, humanidad y apariencia cuasi divina, es un ideal permanente, no restringido a los nuevos príncipes, como cree Viroli.

Con todo, Viroli podría objetar que nuestro análisis ha privilegiado los textos donde Maquiavelo habla del príncipe en general sobre aquellos donde su defensa del mal parece limitarse a los nuevos ocupantes de ese cargo. De hecho,

59 Maquiavelo, N., El Príncipe, cap. 18, p. 169.

60 Véase Mansfield, H. C., «Machiavelli's Virtue», pp. 17-19.

61 Véase Maquiavelo, N., El Príncipe, cap. 14, pp. 137-139.

62 Maquiavelo, N., El Príncipe, cap. 17, pp. 159.

63 Véase Maquiavelo, N., El Príncipe, cap. 7, pp. 67-69. Véase también Discursos sobre la primera década de Tito Livio, trad. A. Martínez Arancón, Alianza, Madrid 2003, libro I, cap. 51, p. 159: «Y fue tan agradecido este presente por la plebe de Roma, que revolucionó toda la ciudad con su alegría, pensando que había recibido un beneficio muy grande, como nunca hubiera esperado y que nunca hubiera pensado en solicitar».

64 Véase, e.g., Mt 6, 1-8; Ерістето, Manual, cap. 1, en: Ерістето, Manual - Disertaciones por Arriano, trad. P. Ortiz García, Gredos, Madrid 2001, p. 3.

65 Maquiavelo, N., Discursos sobre la primera década de Tito Livio, libro II, cap. 2, pp. 198199. Maquiavelo seguramente está pensando en las bienaventuranzas (Mt 5, 3-12). 
Maquiavelo constantemente propone a nuevos príncipes como modelos; por ejemplo, Moisés, Teseo y César Borja. Esto podría leerse como una señal de que ellos solo son modelos para nuevos príncipes, no para todo príncipe. ¿Puede conciliarse ambos rasgos de El Príncipe, su foco en los nuevos príncipes y la apariencia de que el ideal maquiavélico debe ser seguido por todo príncipe? A mi juicio, en ninguna parte de la obra se hallará una respuesta satisfactoria. Para encontrarla hace falta ir a los Discursos sobre la primera década de Tito Livio, donde Maquiavelo dice sin ambages que los reinos, tanto como las repúblicas y los grupos religiosos, perecen en caso de no renovarse, esto es, de no volver a sus instituciones originales o primitivas cada cierto tiempo ${ }^{66}$. El precepto para los príncipes es claro: han de conducir sus asuntos como si fuesen fundadores del dominio que gobiernan. De ahí que los modelos a seguir sean todos nuevos príncipes. Esta es la única manera en que serán poderosos, estarán seguros y alcanzarán la honra, la gloria y la felicidad. Más aún, su honra se elevará, ya que los fundadores de reinos son, después de los fundadores de religiones, los hombres más dignos de elogio ${ }^{67}$. Actuando como fundadores, por tanto, se convertirán en grandes hombres.

Maquiavelo concibe el ideal del gran hombre no como una meta transitoria del príncipe, sino como su más alto y permanente objetivo ético. Pero ¿acaso tiene razón Berlin al declarar que Maquiavelo, junto a este ideal, también considera válido el ideal ciceroniano y cristiano para el príncipe? En el capítulo 15, Maquiavelo enfrenta esta cuestión diciendo:

Y muchos se han imaginado repúblicas y principados que nunca se han visto ni se ha sabido que existieran realmente; porque es tanta la distancia entre cómo se vive y cómo se debe vivir, que quien deja lo que se hace por lo que se debería hacer, aprende antes su ruina que su preservación: porque un hombre que quiera en todo hacer profesión de bueno encontrará su ruina entre tantos que no lo son. ${ }^{68}$

Con estas líneas, Maquiavelo quiere hacer ver a sus adversarios que un ideal ético no puede plantearse ni justificarse al margen de un conocimiento empírico del ser humano, de lo que él realmente puede lograr. Quien proponga un ideal ético que trasciende las posibilidades de los hombres, les exige que dejen de ser hombres. En consecuencia, ese ideal no sirve para juzgarlos buenos o malos en cuanto hombres. En esto consiste para Maquiavelo el error de Cicerón y del cristianismo: que exigen al príncipe lo imposible, y por tanto no le exigen nada en cuanto príncipe. Hablan, más bien, de príncipes imaginarios, ajenos a la realidad efectiva de los asuntos humanos. Mostrar esto es una de las más importantes funciones de los ejemplos históricos que ofrece Maquiavelo. El ideal ciceroniano y el cristiano importan la ruina del príncipe y con ello la

66 Maquiavelo, N., Discursos sobre la primera década de Tito Livio, libro III, cap. 1, pp. 305-311.

67 Maquiavelo, N., Discursos sobre la primera década de Tito Livio, libro I, cap. 10, p. 63.

68 Maquiavelo, N., El Príncipe, cap. 15, p. 147. 
ingobernabilidad del principado y la ruina del pueblo. Por tanto, lo que Cicerón y los profetas llaman virtud y vicio no es más que apariencia de virtud y vicio.

Y que [el príncipe] no se preocupe de caer en la infamia de aquellos vicios sin los cuales difícilmente podría salvar el estado; porque si consideramos todo cuidadosamente, encontraremos algo que parecerá virtud, pero que si lo siguiese sería su ruina y algo que parecerá vicio, pero que, siguiéndolo, le proporcionará la seguridad y el bienestar propio. ${ }^{69}$

El ideal del gran hombre, en cambio, sí es alcanzable; mostrar esto es otra de las importantes funciones de los ejemplos históricos-que Maquiavelo bosqueja a conveniencia, por cierto $^{70}$. Y es el único ideal, a ojos de él, que conjuga la supervivencia del príncipe con la estima de la mayoría de quienes lo observan y de quienes lo recordarán, y por ende con la bondad.

Los atributos que componen este ideal son el único criterio para juzgar buenos o malos a los príncipes. Pero dado que esos atributos son alcanzables solo por quienes son tan hombres como bestias, y así consiguen una apariencia cuasi divina ante sus súbditos, este ideal presenta a un príncipe con la máxima plasticidad posible del carácter, preparado para hacer todo lo que fuere necesario con tal de conseguir y mantener el poder. Contrariamente a lo que sostienen Viroli y Berlin, el cuadro ético que pinta Maquiavelo en El Príncipe es el único válido para el príncipe y a la vez radicalmente opuesto al de Cicerón y al del cristianismo.

\subsection{El ideal y sus restricciones}

Hemos visto que Maquiavelo propone el ideal del gran hombre como el último y único criterio válido para juzgar a los príncipes. Convertirse en un gran hombre es un fin último obligatorio para ellos. Falta, empero, contestar una última pregunta que surge de las interpretaciones que hemos examinado: si acaso este fin último obligatorio es universal, la meta que debe proponerse todo hombre. Berlin cree que sí. A mi juicio, esto es un error.

En primer lugar, Berlin parece olvidar la distinción entre los dos humores. Para Maquiavelo, los seres humanos pueden dividirse en dos grupos: quienes desean dominar y oprimir a otros (los nobles, los altos mandos del ejército, los príncipes) y

69 Maquiavelo, N., El Príncipe, cap. 15, p. 149 (énfasis mío). Estoy por tanto en desacuerdo con la afirmación que Tomás Chuaqui atribuye a Maquiavelo: «el mal, por necesario e ineludible que sea, sigue siendo mal, pero es permisible» (CHUAQUi, T., "La ética política de Maquiavelo: gloria, poder y los usos del mal», p. 182). Por lo demás, es contradictorio pensar algo como malo y a la vez permisible. Si bien Maquiavelo habla de muchos actos que recomienda como «malos», él solo emplea este término para referir a ellos, no para evaluarlos.

70 Sigue en esto a los escritores antiguos: «no se conoce toda la verdad de las cosas antiguas, porque la mayor parte de las veces se ocultan las infamias y se magnifican y amplifican las glorias» (Maquiavelo, N., Discursos sobre la primera década de Tito Livio, libro II, proemio, p. 187). 
quienes desean no ser dominados (el pueblo llano) ${ }^{71}$. Esto quiere decir que algunos hombres no están constituidos de tal forma que pueda aparecérseles como bueno el convertirse en grandes hombres, y por ende no pueden ni deben proponérselo como fin. Esto último solo corresponde a un grupo reducido de la comunidad.

En segundo lugar, ha de notarse que, incluso entre los que desean dominar y oprimir, sus fines no son idénticos. En sus Discursos sobre la primera década de Tito Livio, Maquiavelo repetidamente contrapone el principado y la república. El primero es descrito como un régimen tiránico donde los súbditos carecen de libertad, ya que no existen instituciones mediante las cuales ellos puedan influir a favor de sus intereses, esto es, no ser despojados de su propiedad o dañados físicamente ${ }^{72}$. El segundo, en cambio, es descrito como un régimen en el cual ambas facciones (los grandes y el pueblo llano) tienen cargos de representación para ejercer poder, de modo que sus intereses, aunque contrapuestos, son satisfechos en una medida que, si bien no es total, no genera la disolución de las instituciones y les provee legitimidad ${ }^{73}$.

Como nota Daniel Mansuy en un texto citado anteriormente (sección 2.1.), Maquiavelo concibe la acción política correcta y exitosa como determinada por la necesidad. Por un lado, las personas no eligen su humor, sino que este forma parte de su constitución: para algunos, entonces, el deseo de poder y gloria les es connatural. Por otro, las circunstancias y los talentos naturales propios-en una palabra, su fortuna-constriñen las posibilidades del ejercicio del poder y la satisfacción del deseo natural. Entre estos factores que escapan al control de los grandes, se halla justamente la aptitud de un pueblo para conformar una república o un principado. De hecho, Maquiavelo advierte que un pueblo habituado a vivir en libertad «es sumamente temible» para quien se proponga imponerle un principado ${ }^{74}$; e incluso afirma que el establecimiento de una república allí donde hay gentileshombres es «absolutamente imposible»" ${ }^{75}$. De ahí que, en su exhortación a Lorenzo de’ Medici, Maquiavelo se pregunte retóricamente

si en Italia, actualmente, corrían tiempos que permitieran a un nuevo príncipe adquirir honor, y si había aquí materia [sc. el pueblo] que diera a un hombre prudente y virtuoso la oportunidad de introducir en ella una forma que le honrara a él y proporcionara bienestar a todos los hombres que en ella viven $[\ldots] .{ }^{76}$

71 Véase Maquiavelo, N., El Príncipe, cap. 9, p. 89; Discursos sobre la primera década de Tito Livio, libro I, cap. 4, p. 42.

72 Véase Maquiavelo, N., Discursos sobre la primera década de Tito Livio, libro I, caps. 26, 37, 40, pp. 104-105, 129, 137, donde Maquiavelo, respectivamente, identifica al príncipe nuevo con el tirano; trata la autoridad absoluta como dictatorial y usurpadora de las libertades de los súbditos; y dice que el acto de los decenviros de eliminar los tribunos de la plebe y los cónsules convirtió a Roma en un principado de hecho.

73 Véase Maquiavelo, N., Discursos sobre la primera década de Tito Livio, libro I, cap. 6, pp. 47-52.

${ }_{74}$ Maquiavelo, N., Discursos sobre la primera década de Tito Livio, libro I, cap. 55, p. 174.

75 Maquiavelo, N., Discursos sobre la primera década de Tito Livio, libro I, cap. 55, p. 170.

76 Maquiavelo, N., El Príncipe, cap. 26, p. 257. 
Más aún, no solo destaca este autor la indisposición de los pueblos para uno u otro régimen, sino que además enfatiza que no necesariamente estarán los hombres que podrían instaurar uno u otro ${ }^{77}$. Pues el bien-se lamenta Maquiavelo-incluso entre quienes lo conocen, no siempre puede ser puesto en práctica «por la malignidad de los tiempos o de la fortuna»; a veces no cabe más que esperar que algún otro, «más amado del cielo», lo pueda realizar ${ }^{78}$.

Por tanto, sería imaginario e irrealizable el ideal maquiavélico del buen príncipe-tanto como el ciceroniano y el cristiano-si este fuese obligatorio para todo hombre, incluso para todos aquellos que tienen deseo de dominar y oprimir. Solo si un pueblo es apto para conformar un principado, es decir, si requiere este tipo de régimen para ordenarse, y si además existe un hombre cuyo humor lo impulsa a dominar y cuyos talentos naturales y circunstanciassu fortuna-permiten y requieren que satisfaga su deseo mediante el oficio de príncipe, entonces ese hombre tiene la obligación de convertirse en un gran hombre mediante el oficio de príncipe.

A mi juicio, lo anterior nos ayuda a resolver un dilema que Ernst Cassirer presenta a todos los lectores de El Príncipe: por un lado, dice Cassirer, se nos revela en este libro la más peligrosa y venenosa de las doctrinas; mas por otro, el hombre que las suscribe parece haber sido un buen padre y justo ciudadano, incluso un ardiente republicano ${ }^{79}$.

Este dilema desaparece tan pronto como advertimos que el carácter nosubordinado y obligatorio del ideal de gran hombre propuesto en El Príncipe no implica su universalidad. Lo que Maquiavelo nos presenta es un ideal restringido al oficio de príncipe, oficio que está posibilitado por un sinnúmero de factores ajenos al control de un hombre, y que por ende condicionan la validez del ideal. Los atributos del gran príncipe no tienen por qué ser los del buen padre, los del buen ciudadano, los del buen juez, ni mucho menos los de los gobernantes de una república. Estos últimos, afirma Maquiavelo, no deben actuar como los fundadores de reinos, sino, antes bien, como fundadores de una república ${ }^{80}$. El ejercicio del poder de estos últimos, así como la gloria que puede sobrevenirles por ello, difiere del ejercicio del poder y la gloria de un príncipe tanto como una república difiere de un principado. Me parece temerario, en consecuencia, decir que, para los príncipes y los gobernantes republicanos, «el consejo es idéntico» ${ }^{81}$. Sin duda, Maquiavelo concibe a los gobernantes en uno

77 Véase Maquiavelo, N., Discursos sobre la primera década de Tito Livio, libro I, cap. 55, pp. 170-171.

78 Maquiavelo, N., Discursos sobre la primera década de Tito Livio, libro II, proemio, p. 190.

79 Véase CAssirer, E., The Myth of the State, cap. X, pp. 127-128; cap. XII, pp. 145, 153156. Para el «republicanismo» de Maquiavelo (que no carece de bestialidad, y que es un ideal necesario para ciertas comunidades, pero imposible o poco aconsejable para otras), véase Discursos sobre la primera década de Tito Livio, libro I, cap. 58, pp. 175-181.

80 Véase Maquiavelo, N., Discursos sobre la primera década de Tito Livio, libro III, cap. 1, pp. 305-309.

81 Mansuy, D., «Maquiavelo y la república: notas críticas», p. 113. 
y otro régimen como irremediablemente deseosos de dominación y conquista, pero ello no debe borrar la diferencia entre una y otra forma de organización del poder político.

Los textos revisados en esta sección parecen indicar que la necesidad, esto es, tanto el humor de cada cual como sus circunstancias y talentos naturales (la fortuna que le toca vivir), determina de modo diverso el fin último de cada persona. A diferencia de Tomás de Aquino y tantos otros, para Maquiavelo no hay una única naturaleza humana (o de la razón) que determine uno y el mismo fin para cada uno de nosotros. La validez del ideal de gran hombre esbozado en El Príncipe se ciñe, por tanto, a esos pocos hombres que son impulsados por su humor al dominio y la opresión, y cuya fortuna les abre el camino del oficio de príncipe como único modo de satisfacción de aquel impulso.

\section{CONCLUSIÓN}

Al iniciar esta investigación, se dijo que comúnmente nos representamos a Maquiavelo como un autor que rechaza los ideales éticos de Cicerón y el cristianismo, y que pretende reemplazarlos por una nueva concepción del buen príncipe. A mi juicio, los pasajes analizados en estas páginas muestran que esta lectura es al menos plausible y más convincente que las de Cassirer, Viroli y Berlin.

Con todo, nuestro examen ha puesto de relieve una concepción del buen príncipe muy peculiar en su forma y que matiza en buena medida la interpretación común. Primero, porque se trata de un ideal entendido como fin último obligatorio solo para ciertos hombres que viven en tiempos determinados. Y segundo, porque este ideal, por más terrorífico que parezca, obedece a una percepción de la necesidad en los asuntos humanos. Maquiavelo no es un demonio que se opone al bien que reconoce; para él, las doctrinas platónicas, aristotélicas, estoicas y cristianas carecen de toda validez y conducen al desorden y la ruina de los pueblos. Maquiavelo se resiste a correr la mirada ante el horrendo espectáculo que la necesidad crea en la vida humana. Sus consejos no son el fruto de la ira ni de la desesperanza, sino la cruda descripción de una visión que la experiencia y la historia le han ofrecido de los caminos por los que debe transitar un gobernante para llevar a su comunidad al orden y la prosperidad que le son efectivamente posibles ${ }^{82}$.

Universidad de los Andes (Chile)

RAFAEL Simian

Instituto de Filosofía

rsimian@uandes.cl

[Artículo aprobado para publicación en enero de 2019]

82 El autor quisiera agradecer profundamente las sugerencias y críticas de Manfred Svensson, Daniel Mansuy, Joaquín García-Huidobro y José Antonio Poblete. 